\title{
The Canadian Dollar versus the Collection: How Canadian University Libraries are Coping
}

David R. Scott

Librarian

University of Lethbridge

david.scott@uleth.ca

Nicole Eva

Librarian

University of Lethbridge

nicole.eva@uleth.ca

\begin{abstract}
Through 2015 and into 2016, Canadian academic libraries' collections budgets were severely strained due to the steady decline of the CAD/USD exchange rate. As most subscription fees for electronic resources (e-resources) are billed in US dollars, the falling value of the Canadian dollar significantly reduced libraries' purchasing power. This study is based on a survey of the English-speaking member institutions of the Canadian Research Knowledge Network (CRKN), a Canadian collections consortium, carried out to determine the impact of the poor exchange rate on collection development and how libraries are coping with new budgetary pressures. Librarians from 33 universities provided survey responses. Of these, 22 participated in telephone interviews to further discuss concerns and ideas regarding the current crisis. The study finds that all participant libraries have taken actions to address the budgetary shortfall, including cancelling serial and database subscriptions, negotiating lower costs with vendors, purchasing fewer monographs, and soliciting additional funding from their institutions. While the financial strain resulting from exchange rate fluctuations is indeed a significant problem for which solutions should be sought, several respondents stressed that it only exacerbates the ongoing inflation of e-resource subscriptions. This deeper and enduring issue, which is expected to outlast the present exchange rate crisis, is enabled by an inherently flawed scholarly publishing system. Thus, librarians engaged in discussions with their wider academic communities concerning collections budgets should not focus exclusively on the exchange rate but should leverage the opportunity to explore alternatives to the current scholarly communication model. If solutions exist, they will likely only be achieved through the support of faculty and university administrators, as well as cooperation among post-secondary institutions and library consortia.
\end{abstract}




\section{Keywords}

academic libraries; collection development; serials; electronic resources; exchange rate

\section{Introduction}

This study is based on a survey of the English-speaking member institutions of the Canadian Research Knowledge Network (CRKN), a Canadian collections consortium, carried out to determine the impact of the low exchange rate on collection development and how libraries are coping with new budgetary pressures. Through 2015 and into 2016, Canadian academic libraries' collections budgets were severely strained due to the steady decline of the CAD/USD exchange rate. As most subscription fees for electronic resources (e-resources) are billed in US dollars, libraries' purchasing power was significantly reduced by the falling value of the Canadian dollar.

\section{Background}

The 2015/2016 fiscal year proved challenging for nearly all Canadian post-secondary institutions, and perhaps nowhere was the pressure more acutely felt than in their libraries. As the Canadian dollar dropped to a 14-year low of 0.6821 USD on January 20, 2016 (Bank of Canada, 2016), many academic libraries were left scrambling as their remaining collections budgets rapidly diminished. Because most book purchases and serials subscriptions are paid in US funds, libraries saw their purchasing power severely reduced. This stands in stark contrast to recent history: in November 2007, the Canadian dollar rose to an all-time high of 1.1030 USD and even in July 2011 was worth 1.0630 USD (Bank of Canada, 2016). While in earlier decades libraries struggled with poor exchange rates, it had not been an issue for some time as the Canadian and US dollars had been close to par for several years.

As the CAD/USD exchange rate began its decline in 2013 and worsened through 2014 and 2015, libraries were forced to make cuts. Several university libraries released statements regarding major cancellations. Among the first was Brock University, which cancelled its Wiley-Blackwell subscription of 1,363 journals in December 2014 after the value of the Canadian dollar dropped from 0.9241 to 0.8568 USD between September and December (Cavanagh, 2014). Brock University cited increasing subscription costs, exchange rate fluctuations, and flat budgets the primary reasons for the cancellation. When the dollar continued its drop through 2015 and into 2016, it was no surprise that libraries at several other universities, including Memorial University of Newfoundland (2016) and the Université de Montréal (2016), followed suit, choosing not to renew significant e-resource subscriptions. And the cancellations continue: as recently as September 2016, the University of Ottawa announced that it will be cancelling most of its Taylor \& Francis and Springer journal subscription packages, keeping only 93 of 4,219 titles (2016).

As is seen in the case of Brock University's cancellation of its Wiley-Blackwell subscription, we cannot solely blame the falling value of the Canadian dollar for this 
latest crisis; it only exacerbates an already untenable situation. The crisis began in the 1980s, when journal costs began to escalate (Jones, 2015). The concentration of power in the scholarly publishing world has put academic libraries in a difficult position. They must either pay subscription fees that routinely increase at rates beyond inflation or cancel major journal and database subscriptions on which their students and researchers rely. The year 2015 saw many other libraries cancel large swaths of their eresource subscriptions, often attracting attention from the popular media (see Howells, 2015a \& Howells, 2015b for examples). As news travelled in the Canadian academic community that further cancellations were occurring, and as the University of Lethbridge Library began to grapple with the possibility of having to make significant cancellations, the authors concluded that it would be useful to take a snapshot of how institutions across the country were coping with this confluence of budgetary pressures.

\section{Literature Review}

There has been little recent work done on the effect of currency fluctuations on collection development in libraries, and virtually none from a Canadian perspective. Several articles addressed this issue in the 1980s and, to a lesser extent, the 1990s, but this research tended to focus on the US (Conrad, 1983; Hepfer, 1988; Strauch \& Strauch, 1989; Chressanthis \& Chressanthis, 1994; Dorn, Cox, Hoffer, Powell, \& Mouw, 1995) as well as the UK (Fishwick, 1986), Australia (Burrows, 1993), India (Reddy \& Suseela, 1995), Poland (Howorka, 1995), Tanzania (Kaungamno, 1985), and Ghana (Kedem, 1990). A few studies have been published in the last decade on the topic, but these examined India, the UK, and Malawi, respectively (Kapoor, 2010; Kidd, 2010; Mapulanga, 2012).

Considerably more has been written on the concentration of power in the scholarly publishing industry and the unsustainability of serial subscription price increases. Larivière, Haustein \& Mongeon's 2015 paper, which shows that five companies published over 50 percent of scholarly papers in 2013, has garnered much attention. Some of the issues inherent in the current academic publishing system are succinctly summarized by Horava (2016), who advances a call to action. He contends that to address the concentration of power in the scholarly publishing industry, libraries must carefully analyze the benefits and drawbacks of "big deal" packages as well as initiate dialogue with administrators and faculty alike about the unsustainability of these pricing models and the ways in which current tenure and promotion processes uphold the sacredness of big publishers. However, although librarians are generally familiar with these issues and most libraries struggle with them, few concrete solutions to these problems have been found.

A handful of white papers have been released by library associations and consortia addressing the issue. The Canadian Association of Research Libraries (CARL), an association of Canada's 29 largest university libraries and two federal government libraries, released a white paper outlining the history of scholarly publishing in Canada and potential solutions to the growing power imbalance (Whitehead \& Owen, 2016). To date it provides a fairly comprehensive picture of the scholarly publishing landscape in 
the Canadian context and offers some suggestions concerning how libraries might proceed. The paper emphasizes that knowledge dissemination is a key component of research, that the equilibrium between commercial entities and public institutions has been lost, and that libraries are uniquely positioned to right this imbalance, but only in concert with each other. The authors believe that universities should band together to change the subscription models currently in place and that both universities and funding agencies should focus resources on developing high quality publishing alternatives. It makes no mention of the exchange rate issue, however, nor does it identify actions taken by individual libraries.

One Canadian initiative that has worked towards a more sustainable publishing model is the partnership between CRKN and Érudit, a platform for French-language and bilingual scholarly journals (Ward \& Lavoie, 2016). The two have moved towards a partnership model rather than a strict subscription model, with CRKN members involved in the governance of the Érudit consortium. While the participating libraries still financially support the consortium, the journals managed by Érudit will become open access to the general public. In this way, the two consortia are working together to make scholarly publishing sustainable and fair for both parties. As Johnston, Yates, Coughlan, Moore, \& Burpee (2016) point out, the mere existence of the Canadian Tri-Council policy mandate to make funded research open access has created opportunities for libraries to take a leading role in scholarly communication.

A CRKN white paper released in February 2016 directly addresses the low value of the Canadian dollar and some of the actions CRKN is taking to help its member libraries, such as negotiating invoicing in Canadian dollars and developing foreign exchange projects to help mitigate the impact of currency fluctuations (CRKN, 2016). It also suggested that universities could invest in US dollar accounts when the Canadian dollar is strong to have a supply of "high value" currency. Libraries could then request onetime US funds from their parent institutions to cover the shortfall when the Canadian dollar is low. In addition, the paper notes that 60 percent of Canadian university library acquisitions are purchased in USD, and that 95 percent of CRKN-negotiated licences are invoiced in USD. Given that the CRKN subscriptions are among the largest and most expensive e-resources held by most libraries, it is apparent why so many have recently experienced significant budgetary pressure.

\section{Methodology}

The authors received approval for their Application for Ethical Review of Human Subject Research at the University of Lethbridge on March 7, 2016. Survey invitations were subsequently sent to all $58 \mathrm{CRKN}$ members from English-speaking institutions (see Appendix A for a list of institutions; see Appendix B for the introductory survey text). The authors consulted the libraries' websites to identify the collections coordinator (or a similarly-titled position holder) at each institution. When this information was not available, the authors instead identified the appropriate Associate University Librarian or University Librarian and sent an electronic survey invitation to them. The survey invitation furthermore requested that recipients without extensive knowledge of their 
university's library collection forward the invitation to the appropriate person. The authors requested only one response per institution to ensure equal representation of participating universities in the study results and to avoid duplicating or conflicting information. Initial invitations, including a link to the survey (created using LimeSurvey) were sent on March 7, 2016. A follow-up reminder email was sent on March 21, 2016 (see Appendix C for the survey consent text; see Appendix D for the survey questions). In total, 33 institutions responded-a response rate of approximately 57 percent. Results were tabulated and analyzed using Microsoft Excel.

The survey gave respondents the option of providing their contact information if they were interested in engaging in further discussion by telephone. Following the survey, 22 respondents from different universities participated in follow-up interviews between April 6 and May 2, 2016. The interviews were conducted using the online webinar software Cisco WebEx and were recorded for review and transcription purposes. The interviewers took notes and later transcribed the interviews to facilitate analysis (see Appendix $E$ for the interview questions). As the interviews were intended to be freeflowing, open discussions, the questions were used more as guidelines than as a strict protocol, although all questions were generally addressed during each interview. The researchers analyzed the responses on an interview-by-interview basis, noting specific issues at each institution and then recognizing emerging themes across institutions.

The decision to limit survey and interview respondents to English-speaking CRKN member institutions was largely pragmatic. CRKN's member list provided a concise, useful pool of academic libraries for the study. The researchers chose not to expand the study to college libraries, as doing so would have increased the number of surveyed and interviewed institutions beyond feasibility. In addition, it was deemed important that the study focus on more research-oriented institutions with a greater need for extensive access to scholarly literature. Due to the time and expense that translation would have required, francophone libraries were also excluded. As discussed below, we recognize that this is a limitation of the study, though it should be noted that three primarily English-speaking universities in Quebec were included and consequently that the province was not altogether unrepresented in this research. While the perspectives of librarians at francophone institutions in Quebec and Atlantic Canada would certainly have provided a richer and more complete national picture, it was beyond the scope of this study to include French-speaking university libraries.

\section{Results \& Discussion}

\section{Survey Results}

The 33 survey respondents provided a robust sample that captured the breadth of English-speaking CRKN member institutions. Respondents represented universities located in eight of Canada's 10 provinces (see Figure 1 for a regional breakdown). The number of librarians employed at each institution surveyed ranged from four to 84 and total library staff figures, including librarians, ranged from 11 to 310 . Respondents' annual collections budgets varied widely. Three librarians reported budgets of less than 


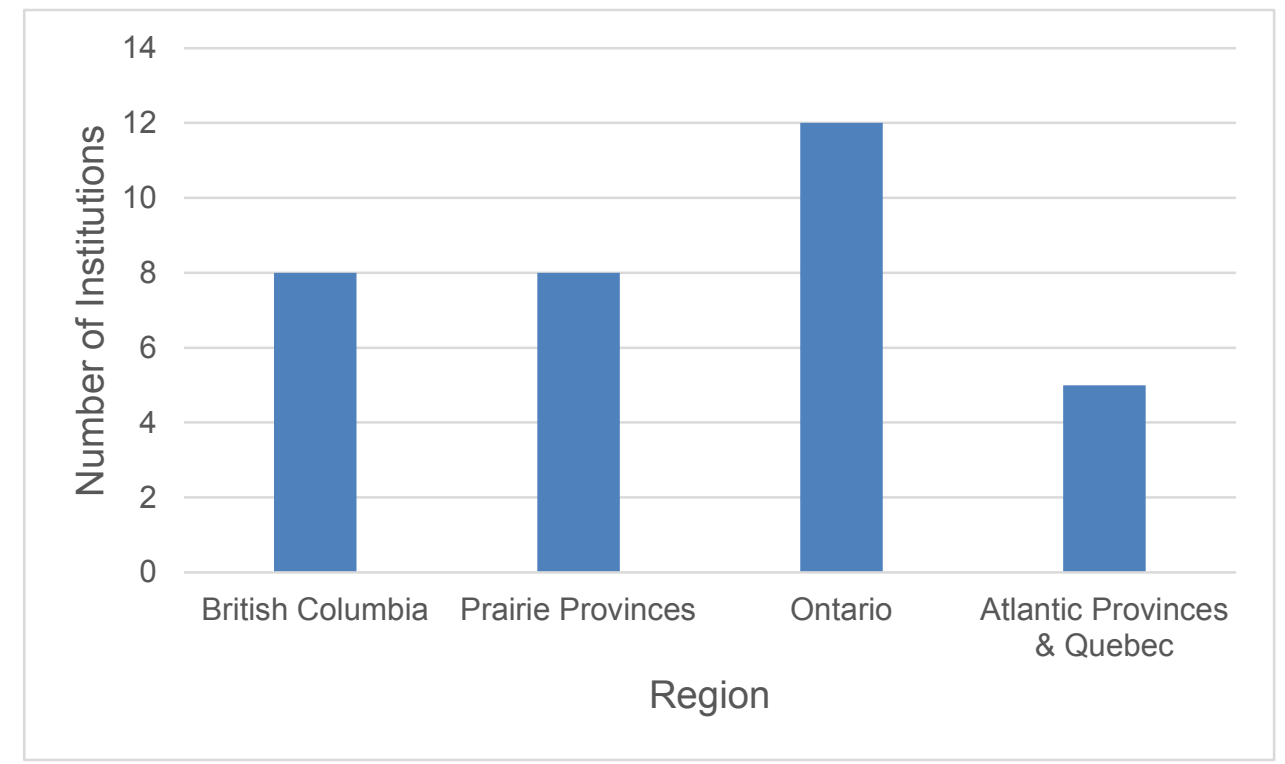

Figure 1. Survey respondents by region.

$\$ 500,000$, while six reported budgets of more than $\$ 10$ million (see Figure 2). Almost one third of respondents reported collections budgets of between $\$ 1$ million and $\$ 2$ million annually.

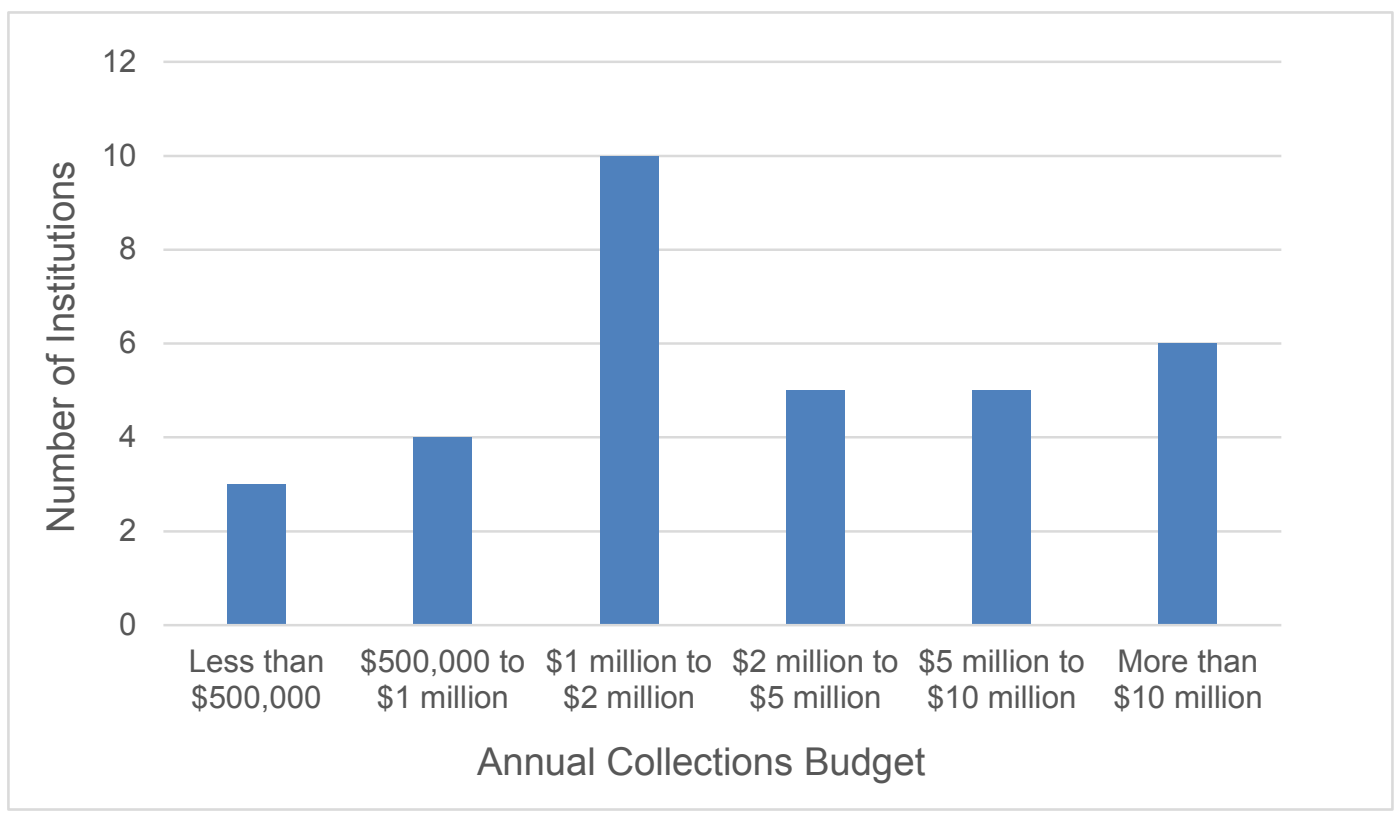

Figure 2. Annual collections budgets of survey respondents.

Trends in collections budgets also varied significantly among universities surveyed (see Figure 3). In the last five years, 46 percent of respondents' collections budgets have increased, while one third have decreased. The remaining 21 percent have been relatively stable. As respondents later related in interviews, several of those collections budgets that have risen have not done so because of regular, ongoing increases, but 
rather due to one-time additional funds allotted to alleviate the pressures posed by the falling value of the Canadian dollar.

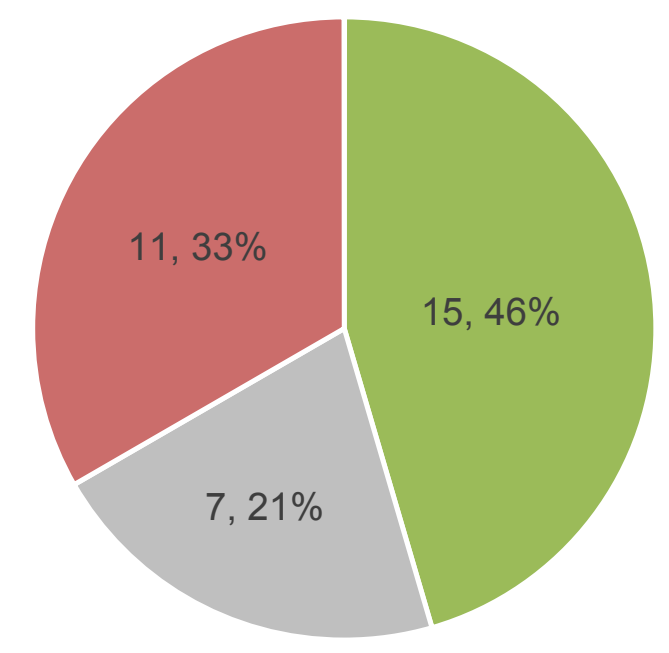

- Increased

- Remained Stable

- Decreased

Figure 3. Five-year trends in annual collections budgets of survey respondents.

Respondents invariably reported that most of their institutions' collections budgets are spent on e-resource subscriptions, including databases and online serials (see Figure 4). All but two surveyed institutions expend between 70 and 89 percent of their collections budgets on e-resource subscriptions. A single respondent reported that their university library system spends over 90 percent of its collections budget on subscription e-resources.

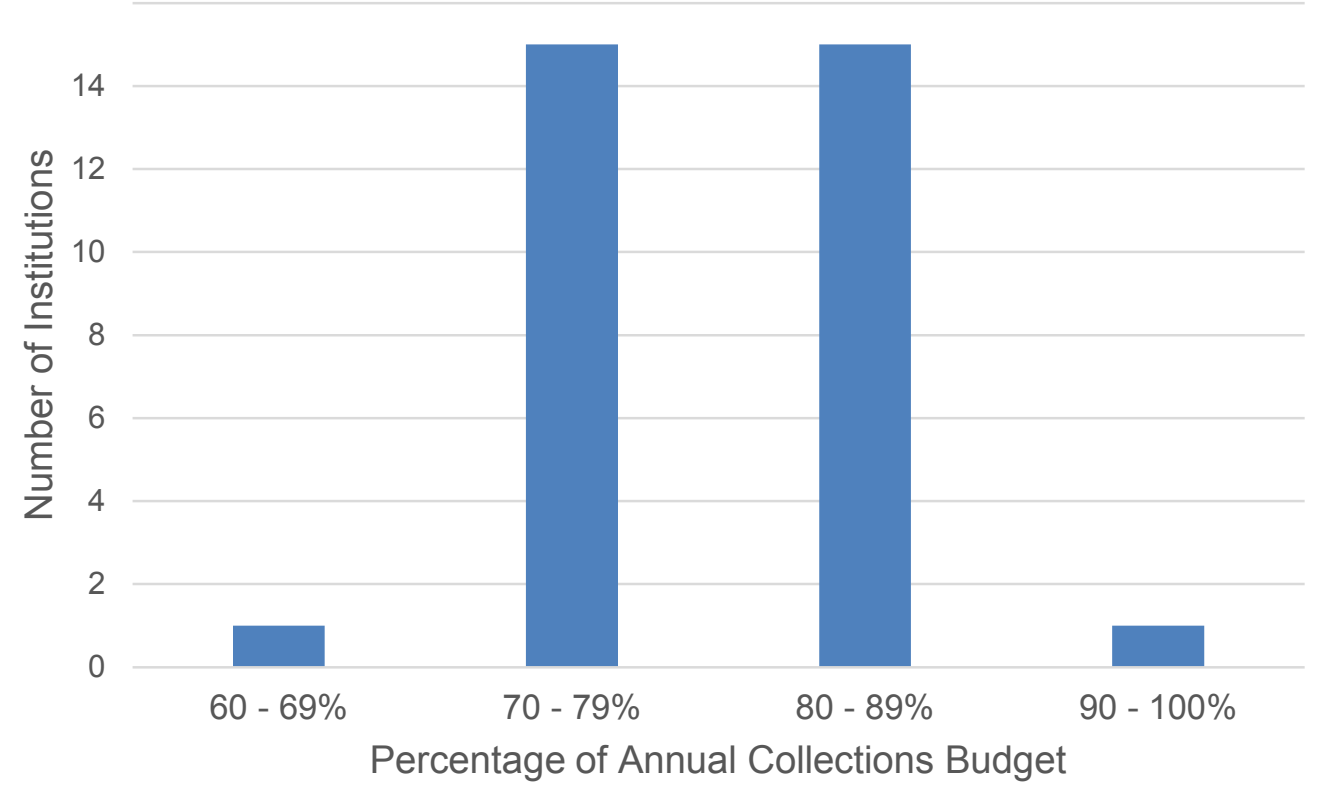

Figure 4. Percentage of annual collections budgets allocated to e-resource subscriptions. 
All libraries surveyed have taken action in response to the decrease in value of the Canadian dollar over the past three years (see Figure 5). More than three quarters of the 33 libraries represented have cancelled both serial and database subscriptions. A similar number have purchased fewer monographs. Approximately 60 percent have negotiated lower costs with vendors. Four of the 33, or about 12 percent, have decreased staffing. One third of respondents reported that their libraries had cut other expenses, such as interlibrary loans and supplies, to cope with recent budgetary pressures. Nineteen of the 33 libraries surveyed have received additional funding from their institutions; however, no libraries reported receiving additional funding from external donors.

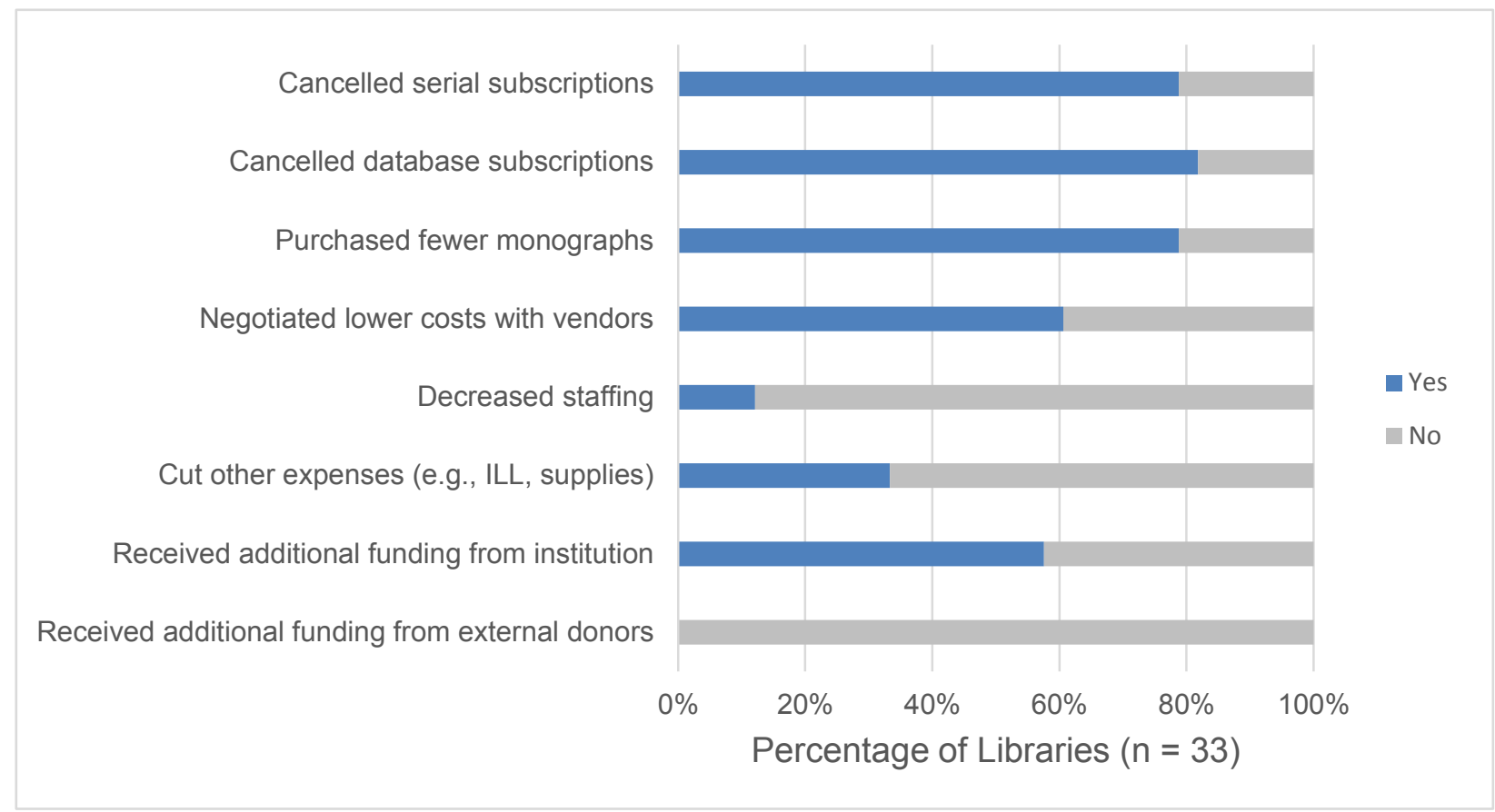

Figure 5. Surveyed libraries' responses to the decreasing value of the dollar.

A handful of survey respondents noted other ways in which their libraries mitigated the impact of the exchange rate on their collections. Multiple institutions purchased US funds in advance so that the costs of subscription invoices from American vendors were more predictable. At least one library delayed posting salaried positions and used the savings to supplement the collections budget. One librarian noted that their library had received funds from certain programs targeted towards the maintenance of subscriptions in particular subject areas. Another respondent added that savings in their library's general budget were transferred to the collections budget. The ability of libraries to take advantage of such alternative measures depends in large part on the funding structures and policies set by their institutions. 
Respondents identified hundreds of database, serial package, and individual journal title subscriptions that their libraries have reviewed and cancelled in the last three years. Among these resources were large, for-profit publisher packages such as Wiley Online Library, SpringerLink, and SAGE Backfiles, as well as academic and professional association publisher packages, such as Cambridge Journals Online and the Royal Society of Chemistry journals. Databases cancelled included Academic Search Complete, America: History \& Life, Anthrosource, BIOSIS Citation Index, CAIRN, EconLit, Érudit, Factiva, Historical Abstracts, LexisNexis, Library Literature \& Information Science, MLA International Bibliography, Nursing Reference Center, SocINDEX, Sociological Abstracts, SPORTDiscus, and Web of Science (see Appendix $\mathrm{F}$ for a list of serial package and database subscription cancellations identified by respondents. Note that the list is not comprehensive, as many respondents only identified the most significant resources cancelled by their libraries). Figure 6 shows the resources which three or more respondents identified as having been cancelled.

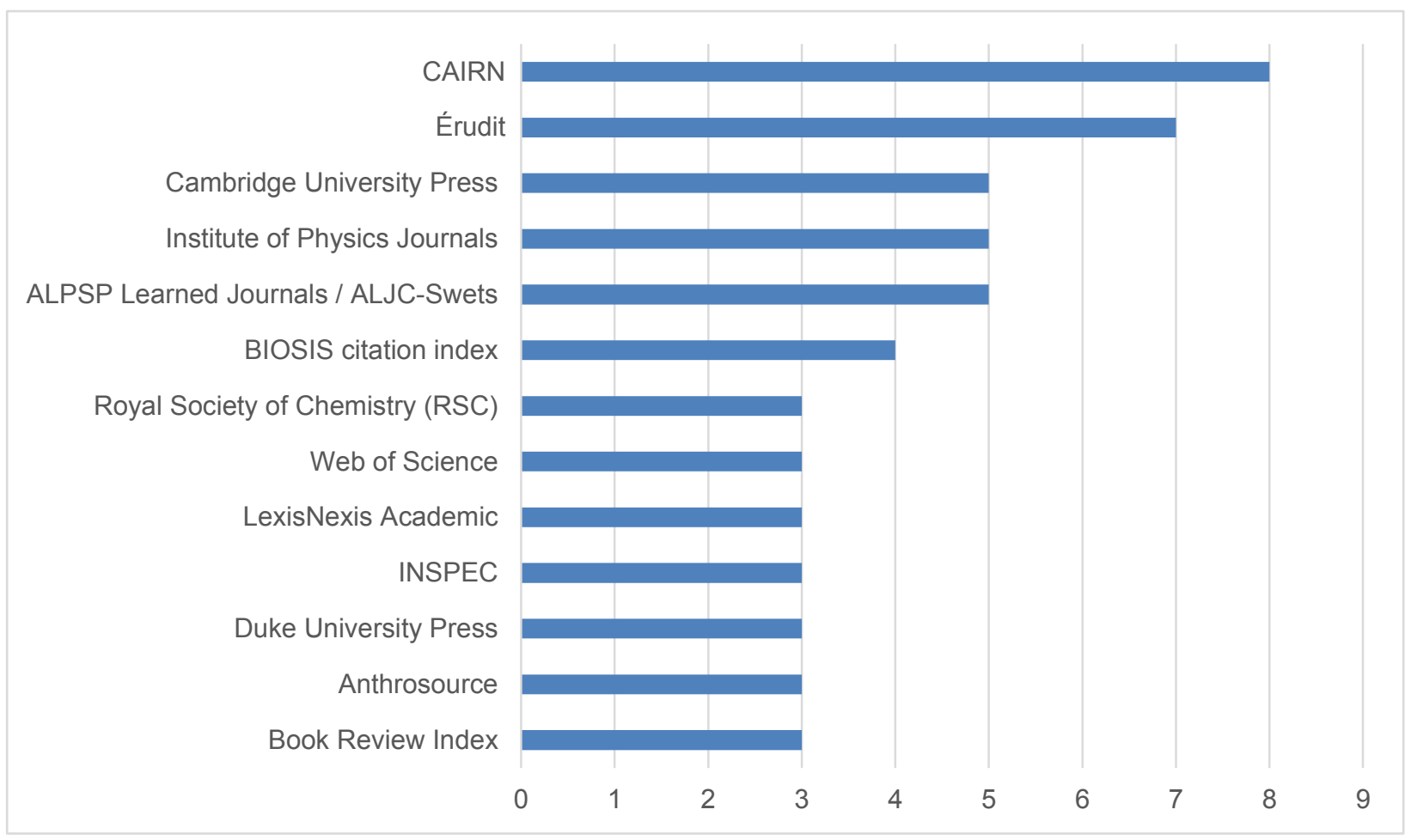

Figure 6. Serial package and database cancellations identified most frequently by survey respondents.

To understand collections librarians' perceptions of the severity of recent budgetary pressures, survey respondents were asked to describe their libraries' response to the decreasing value of the Canadian dollar by selecting one of five options: no response, minor, moderate, major, and extreme (see Figure 7). No respondents selected "no response," and only two chose "minor." Slightly more than half characterized their libraries' responses as moderate, while almost one third described them as major. Four of the 33 surveyed librarians reported their libraries' responses to be extreme. These responses were compared to the size of libraries' collection budgets, but no correlation 
was evident. In the additional comments section of the survey, as well as during the subsequent interviews, many respondents noted that significantly more drastic measures would need to be taken in the coming year if the exchange rate did not improve and funding did not increase.

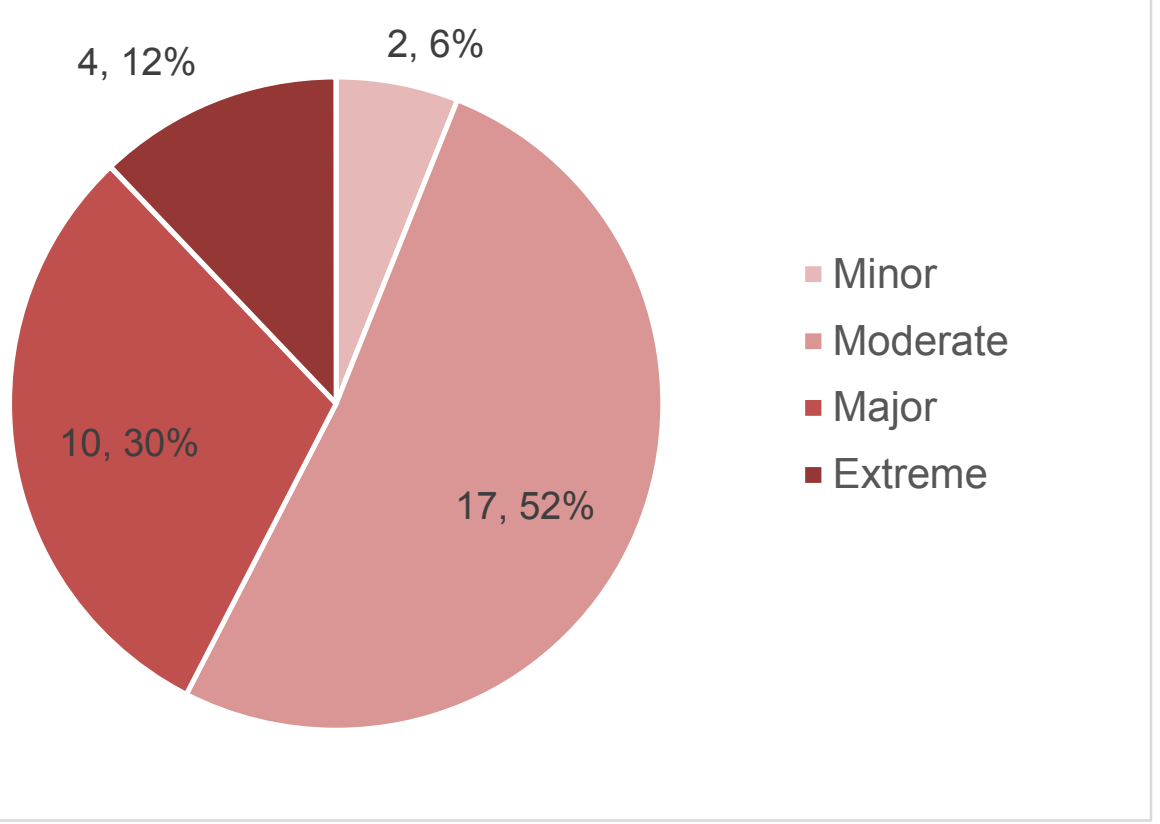

Figure 7. Survey respondents' perceptions of their libraries' responses to the decrease in value of the Canadian dollar.

\section{Interview Responses}

Interviews were conducted with librarians at 22 institutions, accounting for 67 percent of survey respondents and 38 percent of English-speaking CRKN members. Interviewees represented universities in seven provinces and libraries of various sizes, equivalent to that captured in the survey results. Interview responses served to clarify and expand on data collected through the surveys.

\section{Pressures on Collections Budget}

Virtually all interview participants identified the CAD/USD exchange rate as a significant cause of financial strain on their libraries' acquisitions budgets. Most resources, including subscription e-resources, are purchased in US dollars; one librarian noted that 95 percent of their library's licences are paid for in American dollars. Consequently, the drop in the value of the Canadian dollar had a major impact on the ability of the libraries to build and maintain their collections. Several respondents also related that budgetary planning proved very challenging due to exchange rate fluctuations.

In addition to the vagaries of the dollar, most interviewees indicated the inflation of e-resource subscription costs to be an ongoing source of pressure on collections budgets. A few respondents identified this factor as the most important and problematic, 
as it is expected to persist regardless of currency exchange rates. Annual increases in subscription costs routinely outstrip all inflation indices, often by a wide margin, and participants suggested that vendors are putting less effort into justifying price hikes. As one respondent criticized, "[i]t irritates me that big publishers feel entitled to big paycheques." Libraries cannot afford to pay considerably more each year for essentially the same content. Even with modest annual increases to collections funding, subscriptions must be cancelled to maintain a balanced budget. Moreover, most surveyed libraries have not received any funding increases in the last five years, and many have seen cuts.

Other factors cited include lean university and provincial budgets, as well as program expansion. Multiple interviewees explained that their institutions are creating new education and research programming but not providing increased funding to support library acquisitions in new subject areas. As a result, funds are stretched more thinly and existing programs receive less support.

\section{Trends in Cutbacks and Cancellations}

Over 80 percent of interview respondents identified monographs as the resource suffering the largest cutbacks in the face of budgetary pressure. In some instances, the decline in monograph funding has been severe. One institution's monograph budget has fallen over 75 percent since 2002. Another librarian reported a comparable decrease at their university within the last three years. The primary reason why book budgets have experienced exceptional cuts is that spending is flexible and the funds are uncommitted. In the case of e-resource subscriptions, libraries are often locked into multi-year deals and study participants indicated that their users have an expectation that database and serial subscriptions will continue. Monographs are a more convenient target when funds must be found quickly. Several respondents, however, noted that no further decreases could be made to monograph spending without seriously impacting the resources available to those disciplines, particularly in the humanities, which rely heavily on books. Because of this, some libraries have been intentional in protecting monograph budgets in these subject areas.

A small handful of interviewees reported that large numbers of individual serial subscriptions were being cancelled to mitigate overexpenditure. Due to the difficulty of breaking up big deals in a cost-effective manner, independently published journals have been targeted. One respondent conceded that this unfortunately puts pressure on journals to join the big publishers: "we can sort of see that we're perpetuating this cycle, but we haven't found a good way to get out of it."

To be sure, most interview participants reported that their libraries have cancelled serial package and database subscriptions as well, with varying degrees of success. Many have thus far managed to identify resources with relatively low usage, the cancellation of which has not had a significant end-user impact. Librarians at these institutions have generally cautioned that most or all the "low-hanging fruit" has been plucked and that additional cuts would prove detrimental to research and education and perhaps also put 
programs in jeopardy. At other universities, especially those where collections budgets have decreased, librarians have been forced to make cancellations with moderate or high end-user impacts. In some cases, the reaction of faculty has led administrators to increase funding to restore subscriptions.

The extent of e-resource subscription cancellations in recent years varied widely among interview respondents. Some reported savings amounting to less than five percent of their e-resources budgets, while others had made extensive cuts totalling 20 percent or more of their entire annual acquisitions spending. Usually, resources were cancelled due to budgetary pressures; however, in some libraries, subscriptions were not terminated in response to financial need, but because routine review processes had identified them for cancellation for reasons such as low usage and changes to programming.

\section{The Cancellation Process}

Though the processes by which participants' libraries review e-resource subscriptions for renewal or cancellation differ depending on institution size and staffing structure, they generally share much in common. Cost, usage statistics, and cost-per-use figures were cited as among the most important considerations in reviewing an e-resource. A database or serial subscription with a high cost-per-use ratio is typically flagged for thorough review. One interviewee considered $\$ 20$ to $\$ 25$ per use to be the threshold over which a resource would be seriously considered for cancellation, while a librarian at a large institution stated that cost-per-use ratios of over $\$ 5$ were unusual and would require critical evaluation. Other factors playing into review processes include relevance to programming, platform usability, publisher stability, uniqueness of content, discoverability of content, and the extent to which content is peer-reviewed. Interview respondents also explained that even if a database or serial title was not well-used, the subscription was maintained if it was the only resource available for a particular subject area.

Once a resource is tentatively identified for cancellation, consultations with faculty or faculty representatives typically follow. Multiple interview participants noted that some subscription termination decisions have been made solely in-house, without any consultations with individuals or groups outside of the library. This tended to occur either when the e-resource in question was highly multidisciplinary or the cancellation was not anticipated to have a significant impact on users. In certain cases, surveys were sent out to faculty-and less often to graduate students-to inform the review process.

Most interview respondents affirmed that there were e-resources that they would never seriously consider cancelling or that would be very difficult to cancel. Databases and serials with very low cost-per-use figures and resources on which program accreditation depends were identified as subscriptions that must be maintained. Some interviewees, however, suggested that recent budgetary pressures have rendered all subscriptions vulnerable to cancellation. "Nothing is off-limits anymore," one librarian commented. 
Another echoed the assertion, relating that "everything is on the table." In particular, big deal serial bundles have recently come under increased scrutiny at many institutions due to their exorbitant and rising costs. Participants identified Wiley and Taylor \& Francis packages as probable targets in upcoming cancellation decisions. As almost all interviewees believed that additional e-resource cancellations were imminent, Canadian academic librarians will continue to grapple with issues surrounding big deals and their alternatives.

\section{Solutions to the Exchange Rate Problem}

In regards to addressing the problem of the fluctuating exchange rate specifically, interview respondents identified predictability as key and suggested options that might soften the impact of currency volatility on library acquisitions budgets. First, the purchase of US funds, whether carried out by the library or on an institutional or consortial level, allows collections librarians to predict and plan for upcoming expenditures. Second, the ability to carry forward unspent funds into leaner fiscal years can alleviate the effects of exchange fluctuations, though this is not possible for many and perhaps most academic libraries due to institutional policies. Lastly, multiple participants argued that vendors should be willing to bill in Canadian dollars or at a mutually agreeable fixed exchange rate; however, such agreements, if possible, would likely have to be negotiated consortially.

\section{The Deeper Problem: The Traditional Scholarly Publishing Model}

Ultimately, many of the interviewees recognized that the decrease in value of the Canadian dollar, while a significant problem for which solutions may be sought, merely exacerbated a deeper, enduring, and more serious issue - that is, the inflation of e-resource subscriptions made possible by the current scholarly publishing model. Interview participants were asked whether they believed that the fluctuating exchange rate had raised the profile of the academic publishing problem to the extent that action would be taken to stop or mitigate increasing costs or all would return to the status quo as the Canadian dollar regains value. Responses were mixed.

Several librarians were confident that the impact of the exchange rate on library collections would effect deeper change, at least locally. As one librarian affirmed, "[i]t's definitely raised the profile of the library allocations to a much greater degree than it ever was before." Others similarly reported that pressures on their libraries' budgets had put a spotlight on the issue of scholarly publishing and consequently faculty have become more aware of the shortcomings of the current academic publishing model as well as open access alternatives. "I think it has raised the issue to the point that people understand that it's a systemic, structural problem," one participant mused. A few interviewees pointed to increased media coverage as evidence of the situation having come to a crisis point and the potential beginnings of a groundswell favouring change to existing publishing structures. 
Most respondents, however, were less optimistic. "I honestly don't see a whole lot changing," conceded one librarian. "My fear is that it will be the status quo," said another. That librarians are generally familiar with the core issues is not contested; however, many questioned to what extent that understanding has reached faculty and university administrators. As one respondent noted, "I don't think they're all that well informed at all." In reference to faculty, another participant stated: "[t]hey haven't thought about it at all; it has not hit their radar in any way." A few interviewees suggested that because they are insulated from resource acquisition, faculty will remain largely uninformed and perhaps even uninterested until cancellations significantly impede their research and teaching. In few institutions have the budgetary pressures had such a severe impact.

According to respondents, in addition to faculty not comprehending the problems with the current scholarly publishing model, many researchers are not supportive of open access alternatives. Interviewees noted that this is in part because the open access movement has been associated with predatory publishing and in part because faculty may be unaware of the range of open access options available. The assumption, for example, that publishing an open access article necessarily entails the payment of a hefty publication fee, possibly at the expense of hiring a research assistant, would understandably drive many authors away. Consequently, librarians and other informed stakeholders must work to dispel myths regarding open access publishing for researchers to consider it a more viable alternative.

Given the deep-rooted problems with the existing scholarly publishing model, a number of interviewed librarians argued that Canadian academic libraries must take advantage of the opportunity afforded by the Canadian dollar's drop. As one interview participant urged, "[a]s libraries, we have a huge opportunity right now.... We can leverage the problematic exchange rate to our advantage to have a conversation about the unsustainability of the current scholarly communication model." Librarians must be wary of how they frame that conversation, however, as the exchange rate and the publishing model are distinct issues that should not be conflated. The interviewee went on:

My fear is that everything will be too caught up in the US exchange rate and we as a community will spend too much time talking about that and not enough time leveraging that opportunity to talk about what I think the real issue is, which is the scholarly communication crisis.

Another librarian, also concerned about a return to complacency, similarly expressed, "I think that the danger is that... we perhaps have put too much emphasis on the exchange rate."

While solutions to the temporary budgetary constraints caused by the exchange rate are helpful and important, we must not lose sight of the deeper and enduring problem. One interviewee summarized the situation succinctly:

Even if the dollar rises a bit in the next year, the structural problem is still there, and therefore, we have to look at developing a sustainable approach in-house, as well as collaborating at the provincial and national level on strategies that we 
can work on collaboratively to make the environment more sustainable for all of us.

\section{Solutions to the Scholarly Publishing Problem}

Interview participants offered many thoughts on how to address the structural problem. Engagement with faculty was of particular importance. "Faculty culture is the key change that needs to happen," asserted one librarian. As the creators of scholarly information, faculty initially hold the copyright to their work. If faculty were to direct their research through non-traditional, open access channels, the current publication model would be effectively undermined. Changing faculty culture is challenging, however, and takes time, as multiple interviewees attested.

Starting discussions with university administrators was also cited as a critical step. Faculty opt to publish in traditional subscription journals in part because articles in prestigious journals are looked upon favourably in tenure and promotion decisions. If tenure and promotion committees begin to place less value on impact factors and other traditional metrics and deem open access journals to be no less preferable to their subscription counterparts, faculty may be more likely to consider open access options. Librarians, then, should endeavour to inform administrators of scholarly communication issues and encourage the adoption of policies that will promote open access publishing. As one interviewee cautioned, however, these discussions with administrators should not aim at increased acquisitions funding, as larger budgets do not solve the long-term problem and only allow publishers to increase their prices further.

Lobbying the government was also briefly raised as a possible means of bringing change to the scholarly publishing model. A common argument raised by open access proponents is that publicly-funded research should be publicly available. Governments wishing to encourage the dissemination and impact of scholars' work might do so through the creation of legislation mandating a shift to open access publishing. Open access might also be attractive to governments because under the current model, they indirectly pay for-profit publishers large sums of money through post-secondary institution library subscriptions after having already indirectly paid the salaries of the researchers authoring the journal articles. In the Canadian context, this argument is complicated by the fact that provincial governments fund post-secondary education, while legislation favouring open access would most likely be passed at the federal level. Though provincial governments do receive federal funding, this distinction might hinder budgetary considerations from influencing legislation.

Indeed, governments have already begun to act on the issue in Europe (European Council, 2016). Some authorities have expressed concern, however, that a governmentdriven shift may not solve the sustainability problem if article processing charges (APCs) are adopted in place of subscription fees (UNESCO, 2016; Poynder, 2016). Under the APC model, the publishing oligopoly would maintain or increase its hold on scholarly communication and universities would continue to pay exorbitant amounts of money. 
It is worth noting that the Canadian government, while not mandating open access publishing, has policies in place to make the dissemination of federally funded research freely available. Three major Canadian granting agencies-the Canadian Institutes of Health Research, the Natural Sciences and Engineering Research Council of Canada, and the Social Sciences and Humanities Research Council of Canada-known collectively as the Tri-Council, are an important source of scholarly research funding in Canada. Their recent Open Access Policy stipulates that the research they support must be freely available within 12 months of publication (CARL/ARBC, 2015). This is a significant step in the direction of open access in Canadian scholarly publishing. However, there is still much research being done in Canadian institutions that is not funded by these agencies and thus is not required to be made available through open access channels.

Apart from engaging faculty, university administrators, and government bodies, interview respondents suggested that libraries could effect change through their own relationships with vendors, though international, interconsortial collaboration would be necessary. Though consortia such as CRKN, the Council of Prairie and Pacific University Libraries, the Ontario Council of University Libraries, and the Council of Atlantic University Libraries have been invaluable in negotiating lower subscription costs for member institutions, Canadian academic libraries alone do not exercise the buying power to effect significant change in the global scholarly communication system. As one interviewee remarked, "[q]uite frankly, we're a drop in their [vendors'] bucket." If libraries are to put significant pressure on vendors, the effort must be united and cross international borders. Moreover, the aim should not be to merely reduce costs, but to bring deep and enduring change to the scholarly communication model. One participant asserted that the most effective way in which libraries might spur such change would be to collectively walk away from the negotiating table altogether, thus instigating a widespread crisis. They acknowledged, however, that it would be very challenging to achieve unity in such an endeavour.

To be sure, many interview respondents noted that efforts to promote open access are already underway. Libraries are building and improving institutional repositories. New scholarly communications librarian positions are being created and filled. Some universities have allocated funds from which authors may draw to publish open access articles. Librarians have received invitations to present on scholarly communications issues at faculty councils. One interviewee related that their university's mathematics department is spearheading an open access initiative. Another librarian noted that a campaign is underway at their institution to adopt an open access policy. Multiple participants pointed to CRKN's Institutional Mobilization Toolkit (2016) as a consortial effort to raise awareness concerning scholarly publishing issues.

In these and other ways, libraries are already drawing attention to problems with the current academic publishing model and promoting alternatives. Whether it is enough, however, remains to be seen. 


\section{Further Discussion}

This cross-Canada snapshot of the collections budget pressures that academic libraries are trying to cope with is perhaps not surprising. The drop in value of the Canadian dollar against the US dollar has certainly put significant strain on acquisitions funds. The rapid decrease in purchasing power due to the fluctuating exchange rate is an important problem for which solutions should be sought. However, most librarians interviewed recognized that the weak Canadian dollar has exacerbated a deeper and more enduring problem: the unsustainable and unreasonable inflationary costs of e-resource subscriptions. The message that our scholarly communication system is broken must not be lost in discussions about the currency exchange rate. Several librarians expressed concern that as the Canadian dollar regains value, the ongoing issues confronting library budgets will once again fade into the background. The struggles that collections librarians face due to subscription increases is too often invisible to university administrators and faculty. The crisis fuelled by the falling exchange rate has allowed some librarians to bring this discussion to the forefront of their organizations. Librarians have seen this as an opportunity to extend the discussion beyond the current crisis and engage our academic communities more fully in efforts to seek alternatives to the current scholarly publishing system.

Unfortunately, there does not appear to be an easy solution. The librarians interviewed generally did not believe that there is any clear way to break free of the publishing model. Open access is one possible answer, though several interview participants were doubtful that the open access movement will effect significant change. Many expect that as the present crisis passes, the status quo will persist and deeper, systemic change will remain elusive, at least in the near future. Some librarians stated that now is an ideal opportunity to challenge the current model—whether by cancelling major packages or fully embracing open access alternatives-but they were in the minority. Most felt powerless to bring about change in any meaningful way. There is some hope, however, that through engaging faculty and administrators in a discussion about open access alternatives that we can move away from our dependence on for-profit scholarly publishers and create a new, more ethical and financially sustainable model of scholarly communication.

\section{Limitations of Study and Further Research}

The exclusion of francophone universities is a significant limitation of this study. Frenchspeaking institutions must balance the acquisition of French-language resources, which may be purchased in Euros, with the development of English-language collections, as most scholarship is published in English. How francophone libraries are maintaining this balance as currency exchange rates fluctuate is a question that this study cannot answer. More specifically, the manner and extent to which language is considered in e-resource cancellation decisions in these libraries is not examined in this research. The use of qualitative data analysis software (such as NVivo) to analyze the interviews may also have strengthened the study; however, because the authors wished to gather and 
publish the results promptly, the time investment required to learn and use such software outweighed the potential benefits.

Going forward, the findings of this study may be built upon in many ways. It is the authors' hope that this article will stimulate discussion among academic librarians and their larger academic communities on the crisis facing libraries across the country. An exploration of francophone libraries' responses to budgetary pressures would provide a more complete national picture and answer the questions identified above. A follow-up survey of study respondents conducted after one or two years could offer information on whether libraries followed through on tentative cancellations, restored previously cancelled subscriptions, or made permanent changes to acquisition budget models. A future study may also determine whether the current budget crisis will indeed bring change to the scholarly communication system in Canada, or that the status quo will remain as the Canadian dollar regains value, as several interview respondents feared.

\section{Conclusion}

Some libraries have mitigated the impact of the Canadian dollar's decreased value on their collections budgets through negotiating Canadian invoicing, negotiating a fixed exchange rate, purchasing US funds when the Canadian dollar is stronger, receiving emergency funds from their institutions, and other financial measures. However, interviewed librarians argued that these efforts may not be addressing the deeper issue, which will persist regardless of exchange rate fluctuations. The flawed scholarly communication model is a distinct problem that will require its own solutions. It is likely that only with institutional and perhaps government support will we be able to take steps toward creating an alternative system of scholarly publishing that will allow all academics access to current research in a financially sustainable way. If reputable open access alternatives are embraced both by authors and those on their tenure and promotion committees, we might collectively sidestep the for-profit publishers and create a new scholarly communication model independent of the current oligopoly. Such a task will certainly be impossible for any one institution to accomplish alone, but with inter-institutional and interconsortial cooperation, it may be achievable.

\section{References}

Bank of Canada. (2016). CAD/USD Exchange Rate Lookup.

Burrows, T. (1993). Exchange rates, Australian libraries and serials subscriptions. Australian and New Zealand Journal of Serials Librarianship, 4(2), 19-24.

Canadian Association of Research Libraries. (2015, May). Tri-Agency open access policy on publications: Quick answers! Canada: Author.

Canadian Research Knowledge Network. (2016, February). University library acquisitions budgets: Foreign exchange risk and CRKN. 
Canadian Research Knowledge Network. (2013). Institutional mobilization toolkit.

Cavanagh, K. (2014, December 4). Brock Library forced to shed journal subscription costs. The Brock News.

Chressanthis, G. A. \& Chressanthis, J. D. (1994). A general econometric model of the determinants of library subscription prices of scholarly journals: The role of exchange rate risk and other factors. Library Quarterly, 64(3), 270-293.

Conrad, L. (1983). The effects of foreign currency exchange rate fluctuation on serials budget estimating. Serials Librarian, 7(4), 65-66.

Dorn, K., Cox, J., Hoffer, H., Powell, A., \& Mouw, J. (1995). The balance point: Exchange rates and the serials marketplace. Serials Review, 21(3), 83-96.

European Council. (2016, April 6). EU action plan for open science. New Europe.

Fishwick, F. (1986). The effects of unstable exchange rates on the prices of books and journals. In R. M. Burton (Ed.), Serials '86: Proceedings of the UK Serials Group Conference, University of Exeter, 24-27 March 1986 (pp. 70-87). Oxford: UKSG.

Hepfer, C. (1988). Serials pricing: The impact of exchange rates and currency trends. Serials Librarian, 15(3/4), 141-143.

Horava, T. (2016, March/April). Dollars and decision-making: The oligopoly of academic publishing - what does it mean for us? Technicalities, 36(2), 10-14.

Howells, L. (2015a, December 8). Memorial University to cancel thousands of journal subscriptions. CBC News.

Howells, L. (2015b, December 13). Ryerson University says it must cancel journal subscriptions, like MUN is considering. CBC News.

Howorka, B. (1995). Devaluation and the library. Poradnik Bibliotekarza, (1), 13-15.

Johnston, D., Yates, E., Coughlan, R., Moore, P., \& Burpee, K. J. (2016, January 27). Canada's new open access policy: Integrating libraries into open scholarship. Paper presented at Ontario Library Association Superconference, Toronto.

Jones, W. (2015). Deciding crises in academic libraries. Media Tropes, V(2), 111-114.

Kapoor, K. (2010). Impact of exchange rates on periodicals subscription in Indian libraries. Collection Building, 29(3), 91-97. 
Kaungamno, E. E. (1985). The case of Tanzania library services. Canadian Library Journal, 42(4), 185-187.

Kedem, K. A. (1990). The acquisition of periodicals in a foreign exchange starved library: The case of the Balme library. Serials Librarian, 18(1/2), 173-180.

Kidd, T. (2010). The view from the U.K.: The economic crisis and serials acquisitions on an offshore island. Serials Librarian, 59(3/4), 384-393.

Larivière, V., Haustein, S., \& Mongeon, P. (2015). The oligopoly of academic publishers in the digital era. PLOS ONE, 10(6), e0127502.

Mapulanga, P. (2012). Structural adjustment policies, currency devaluation and liberalised exchange rate on library acquisitions in the University of Malawi Libraries. The Bottom Line: Managing Library Finances, 25(3), 123-134.

Memorial University of Newfoundland. (2016). Journal subscription consultation 2016.

Poynder, R. (2016, May 30). The OA interviews: Michaël Bon, founder of the SelfJournal of Science.

Reddy, Y. N. \& Suseela, V. J. (1995). Periodical prices in relation to mailing charges, foreign exchange and inflation. IASLIC Bulletin, 40(3), 107-116.

Strauch, B. \& Strauch, K. (1989). Foreign exchange rates and journal pricing. Library Acquisitions: Practice and Theory, 13(4), 417-422.

UNESCO. (2016). Joint COAR-UNESCO statement on open access.

Université de Montréal. (2016, May 6). Cancellation of subscriptions to 2,116 Springer journals.

University of Ottawa. (2016, September 23). Collections update - September 2016.

Ward, M. \& Lavoie, J. (2016). A library-publisher partnership for open access: Building an innovative relationship between scholarly publishers and academic libraries. LIBER Quarterly, 25(4), 189-204.

Whitehead, M. \& Owen, B. (2016, February 22). Canadian universities and sustainable publishing (CUSP). Canada: Canadian Association of Research Libraries. 


\section{Appendix A: English-speaking CRKN Institutions}

Acadia University (NS)

Algoma University (ON)

Athabasca University $(A B)$

Bishop's University (QC)

Brandon University (MB)

Brock University (ON)

Cape Breton University (NS)

Carleton University (ON)

Concordia University (QC)

Concordia University of Edmonton (AB)

Dalhousie University (NS)

Kwantlen Polytechnic University (BC)

Lakehead University (ON)

Laurentian University (ON)

MacEwan University (AB)

McGill University (QC)

McMaster University (ON)

Memorial University of Newfoundland (NL)

Mount Allison University (NB)

Mount Royal University (AB)

Mount Saint Vincent University (NS)

Nipissing University (ON)

NSCAD University (NS)

OCAD University (ON)

Queen's University (ON)

Royal Military College of Canada (ON)

Royal Roads University (BC)

Ryerson University (ON)

Saint Mary's University (NS)

Simon Fraser University (BC)
St. Francis Xavier University (NS)

The King's University (AB)

Thompson Rivers University (BC)

Trent University (ON)

Trinity Western University (BC)

University of the Fraser Valley (BC)

University of Alberta (AB)

University of British Columbia (BC)

University of Calgary (AB)

University of Guelph (ON)

University of Lethbridge (AB)

University of Manitoba (MB)

University of New Brunswick (NB)

University of Northern British Columbia

(BC)

University of Ontario Institute of

Technology (ON)

University of Ottawa (ON)

University of Prince Edward Island (PE)

University of Regina (SK)

University of Saskatchewan (SK)

University of Toronto (ON)

University of Victoria (BC)

University of Waterloo (ON)

University of Windsor (ON)

University of Winnipeg (MB)

Vancouver Island University (BC)

Western University (ON)

Wilfrid Laurier University (ON)

York University (ON) 


\section{Appendix B: Survey invitation}

Dear

We are conducting a study of the effect that the depreciation of the Canadian dollar is having on the collection budgets of Canadian academic libraries. As librarians at the University of Lethbridge, we have seen the great impact this has had on our own budget, and as we grapple with solutions we find ourselves wondering how other libraries are coping with this issue.

We would sincerely appreciate if you could take 5-10 minutes to fill out our brief survey; we are sending it to all English-speaking CKRN member libraries. We would also like to conduct follow-up telephone interviews on this topic, so would appreciate if you opt in to that as well; however, even just the survey response will be immensely helpful. If you are not the collections coordinator for your institution, please forward this email to the most appropriate individual. Also, note that we are requesting that only one survey be submitted per institution; if your university has multiple libraries, please respond to survey questions on behalf of all of the libraries collectively, to the best of your ability.

Please follow the link below to complete the survey: https://www.uleth.ca/lib/surveys/index.php?r=survey/index\&sid=545946\&newtest=Y

We plan to publish our findings so that all Canadian academic libraries will be able to see how other institutions are dealing with this very real budget crisis. We thank you in advance for your time.

Sincerely,

David Scott \& Nicole Eva

Librarians

University of Lethbridge 


\section{Appendix C: Survey consent}

\section{Survey of Canadian Academic Libraries regarding the impact of the Canadian Dollar}

Please read the following letter of information carefully before beginning the survey:

Principal Investigators: David Scott \& Nicole Eva, Librarians, University of Lethbridge

What is this study about?

You are invited to participate in a survey of collection managers/coordinators at postsecondary academic institutions in Canada. This is a study of the impact the deflation of the Canadian dollar is having on the collection budget of these institutions, and the ways they are coping with that pressure. We would like to share these results so that we all have a better idea of what other libraries across the country are doing.

What is expected of you?

The survey contains between ten and sixteen questions (some are conditional) and will take about five to ten minutes to complete. For those interested, we would like to follow up with a 20 minute telephone interview.

What are the anticipated uses of the data collected?

The responses to the survey will be aggregated and analysed for publication/ presentation purposes. All data will be anonymized.

What are the risks and benefits of participating?

There are no anticipated risks from participating in this study. The published results will be of benefit to all Canadian academic libraries as we struggle with our decreasing purchasing power.

How will your confidentiality and anonymity be protected?

We ask you to identify your institution for our own record keeping and analytical purposes; however, survey data will be anonymized in publication. Because the survey is being administered via the Internet, there is a risk that data will be intercepted. We are also asking, for those who consent, for the contact information of the survey-taker to follow up with more in-depth questions. Please be assured that any identifying information, be it personal or institutional, will be kept in strict confidentiality by the researchers and will only be made public with your consent. The responses to this survey will be kept on a password-protected computer with access restricted to the investigators, and will be deleted five years after data collection has been completed. If you provide consent to a follow-up telephone interview, we will likewise keep any 
information you give us confidential and password-protected, and will anonymize any comments you provide unless you have given explicit permission to identify yourself or your institution. Otherwise, all comments from interviews will be anonymized, and all institutional data reported in the aggregate so as not to single out identifying factors.

The survey is administered through LimeSurvey. To read LimeSurvey's data protection statement, follow the link below:

https://www.limeservice.com/en/home/21-english/general-content/39-data-protectionstatement

How can a participant withdraw?

Your participation is completely voluntary. You may withdraw your participation at any time without penalty or loss of benefits to which you are otherwise entitled by simply closing your browser before you submit your responses and they will not be included. If you choose to discontinue participation after you have submitted your responses, contact the researchers with a request to withdraw your submission, we will delete the data from our results. Likewise, if you have participated in a follow-up telephone interview and later decide you do not want us to use the information you provide, contact either researcher directly, and we will delete your comments from our files. The researchers' contact information may be found below.

Who is conducting this research?

For more information on this study or for a summary of the findings (available after September 2016), you may contact the investigators at nicole.eva@uleth.ca / 403-3292588 or david.scott@uleth.ca / 403.329.5178. Questions regarding your rights as a participant in this research may be addressed to the Office of Research Ethics, University of Lethbridge (Phone: 403-329-2747 or Email: research.services@uleth.ca). This research study has been reviewed for ethical acceptability and approved by the University of Lethbridge Human Subject Research Committee.

If you wish to participate in the survey, please proceed to the questions now by simply clicking on the "next" button. Submission of your responses will be accepted as implied consent to participate. Thank you in advance for your participation.

Nicole Eva \& David Scott University of Lethbridge Library 


\section{Appendix D: Survey Questions}

\section{Academic Libraries' Responses to the Decreasing Value of the Canadian Dollar}

1. Please identify your institution. This information will be kept confidential.

2. Approximately how many librarians are employed by your institution?

3. Approximately how many library staff, excluding librarians, are employed by your institution?

4. What is your library's annual collection budget? Choose one of the following answers.

0 Less than $\$ 500,000$

$0 \$ 500,000$ to $\$ 1$ million

$0 \quad \$ 1$ million to $\$ 2$ million

$0 \$ 2$ million to $\$ 5$ million

$0 \quad \$ 5$ million to $\$ 10$ million

0 More than $\$ 10$ million

5. Has your library's annual collection budget increased, remained stable, or decreased over the last five years? Choose one of the following answers.

0 Increased

0 Remained stable

0 Decreased

6. Approximately what percentage of your library's annual collection budget is spent on electronic resource subscriptions (i.e., database and electronic serial subscriptions)? Choose one of the following answers.
$0 \quad 0-9 \%$
$0 \quad 10-19 \%$
$020-29 \%$
$0 \quad 30-39 \%$
0 $40-49 \%$
$0 \quad 50-59 \%$
$060-69 \%$
$070-79 \%$
$0 \quad 80-89 \%$
o $90-100 \%$

7. In what ways has your library responded to the decreasing value of the Canadian dollar over the past three years? Check all that apply.

Cancelled serial subscriptions

Cancelled database subscriptions

Purchased fewer monographs

Negotiated lower costs with vendors

Decreased staffing

Cut other expenses (e.g., ILL, supplies)

Received additional funding from institution 
Received additional funding from external donors

$$
\text { My library hasn't made any changes }
$$

Other:

8. What are the most noteworthy serial title/package/publisher subscriptions your library has cancelled in the last three years?

9. What are the most noteworthy database subscriptions your library has cancelled in the last three years?

10. How would you describe your library's response to the decreasing value of the Canadian dollar over the past three years? Choose one of the following answers.

0 No response

0 Minor

0 Moderate

0 Major

0 Extreme

11. Do you have anything to add?

12. Would you be willing to participate in a telephone interview to discuss the above questions further?

13. What is your name? (Note: Your responses to this question and the three following questions will be kept confidential and used only to contact you for a telephone interview.)

14. What is the title of your position?

15. What is your office phone number?

16. What is your email address? 


\section{Appendix E: Telephone interview questions}

At the beginning of the telephone interview, we read the following statement aloud:

Have you received and read the consent form that we emailed with our meeting invitation? You understand that your participation is completely voluntary and that you may withdraw at any time? Do you understand that the interview will be audiorecorded? Do you wish to proceed with the interview? Your verbal response will be accepted as consent to participate.

- What factors are putting the most pressure on your collections budgets today?

- What do you think is getting the hardest hit in your collections budgets due to financial pressure?

- If you have cancelled journals or databases, which ones have you cancelled? [taking into account the ones they have already mentioned]

- How much have you saved through these cancellations?

- How did you arrive at any cancellation decisions? Did you do consultations? Do you have a specific process you go through to make these decisions? Do you have a base of journals/databases which you will never touch?

- Based on what you have cancelled so far, what do you see happening going forward?

- Has this changed or are you thinking of changing the way you allocate your budgets? (For example, if formerly money was given to subject areas for discretionary purchases, has this changed?)

- Do you think the compounding effect of the dollar combined with the ongoing issue of the cost of scholarly publishing has raised the profile of this issue among both librarians and faculty - to the point of potentially taking some kind of action to stop/mitigate this increase? Or do you think it will be status quo, especially as the dollar regains value? What do you think some long-term solutions might be? Have you seriously discussed these in your library? 


\section{Appendix F: Mentions (by institution) of specific package/database cancellations}

Database Title

Academic Search Premier OR Complete

Access World News

Mentions

Accessible Archives

ACM Digital

Adam Matthew (8 collections)

Aerospace Database

Africa Knowledge Project

Agricola (EBSCO)

Alexander Street Press Counseling \& Therapy

in Video

ALPSP Learned Journals / ALJC-Swets 5

America History \& Life

American History in Video

American Physical Society

American Reference Books Annual

American Society for Microbiology (ASM)

(partial)

Anthrosource

Applied Science and Technology Full-Text (EBSCO)

ARTbibliographies Modern

ATLA

Berkeley Electronic Press

Biography and Genealogy Master Index

BioOne

BIOSIS

Birds of North America Online

Book Review Digest Plus

Book review index

Books 24/7 (ITPro \& BusinessPro Collections)

British Humanities Index

Britannica Online

Business Source Elite

BusinessWorks (Kluwer) 2

Cabell's directories 2

CAIRN

CARD 1

Canadian Business Resource 1

Canadian Electronic Library 1 
Canadian Labour Law Reporter 1

Canadian Periodical Index 1

CollegeSource online 1

Cambridge University Press $\quad 5$

$\mathrm{CCH}$ (Law)

Chicago Complete Journal Package 1

Communication Abstracts 1

Compendex 2

CRC e-books 1

CSA (Codes \& Standards)

Current Chemical Reactions 1

Datastream 1

De Gruyter Journals 1

Dictionary of Economics 1

Dominion Bond Rating Service DBRS 1

Duke University Press Journals 3

Earthquake Engineering Abstracts 1

EconLit 1

e-Duke Books 2

eHRAF Collection of Archaeology 1

eHRAF World Cultures 1

Emerald Management Collection 2

Encyclopedia of Islam 1

EngNetBase 1

ENVIROnetBASE 1

Environment Index (EBSCO) 1

Érudit

Eureka.cc 1

Eurocode 1

Factiva (partial) 1

Facts on File 1

Faulkner's advisory for IT studies 1

Films on Demand 1

Foundation Directory 1

Freedonia Focus Reports 1

Gale Literature Resource Centre 2

Global Books in Print 1

Grove Music Online 1

Health Source Nursing/Academic 1

Henry Stewart Talks 1

Historical Abstracts 1

Hoovers Company Profiles 1 
Humanities Abstracts (EBSCO) 2

IEEE (partial) 1

IMF eLibrary 2

InCites 1

INSPEC 3

Institute of Physics Journals 5

Institution of Civil Engineers (ICE) 1

International Pharmaceutical Abstracts 1

JoVE 1

J.P. Morgan Research 1

Key Business Ratio 1

LegalWorks (Kluwer) 1

LexisNexis Academic 3

LexisNexis Corporate Affiliations 1

Library Literature \& Information Science Full

Text

Maney Publishing (Taylor \& Francis) 1

Marclt Annual Services 1

MarketResearch.com Academic 1

MathSciNet 1

Media Technology Monitor 1

Merck Index 1

Microlog microfiche 1

MLA Bibliography 1

Music Index 1

Nature (partial) 2

NetBase 1

NRC Research Press 1

NTIS (National Technical Reports Library) 1

Nursing Reference Centre (EBSCO) 1

OCLC Worldcat 1

OECD iLibrary 1

Oxford Online 1

OxResearch 1

PAIS International 2

Palgrave Journals 1

Passport/GMID 2

Past Masters 1

Portland Press 1

Project MUSE (partial) 1

ProQuest Accounting \& Tax 1

ProQuest Asian Business \& Reference 1

ProQuest Digital Dissertations/Dissertations \& 2 
Theses

ProQuest Research Library 1

PsychArticles 1

Reference Universe 2

Refworks 2

Research Now 2

Retrospective Index to Music Periodicals

(RIPM) 1

Royal Society of Chemistry (RSC) 3

SAE Digital Library 1

Safari Tech Books 2

Sage Deep Backfile 1

Sage Knowledge Books 1

Snapshots North America 1

Social Sciences Index 1

SocINDEX 1

Sociological Abstracts 1

Sports Business Research Network SBRN 1

Springer (partial or full) 2

SpringerLink e-books 2

SpringerMaterials 1

SRDS business media advertising source 1

SRDS consumer media advertising source 1

Standard \& Poor's NetAdvantage 2

Sustainalytics 1

TaxWorks (Kluwer) 1

Taylor \& Francis SSH 1

ValueLine 1

VAST Academic Video Database 2

Wall Street Journal (historical) 1

Washington Post (historical) 1

Web of Science 3

World Advertising Research Center (WARC) 1

World Bank Library 1

World History in Video 1

World Politics Review 1

In addition, many individual journal titles, various print directories, abstracting and indexing databases, full text databases, e-book package front files, journal back files, an unnamed streaming video package, and various association memberships were also mentioned as having been cancelled. 